\title{
Geometrically non linear analysis of functionally graded material plates using higher order theory
}

\author{
J. Suresh Kumar ${ }^{1}$, B. Sidda Reddy ${ }^{2, *}$, C. Eswara Reddy ${ }^{3}$, K. Vijaya Kumar Reddy ${ }^{4}$ \\ 1.4. J.N.T.U.H. College of Engineering, Kukatpally, Hyderabad, A.P, INDIA \\ ${ }^{2}$ R.G.M. College of Engineering \& Technology, Nandyal, A.P, INDIA \\ ${ }^{3}$ Director, Sri Padmavathi Mahila Visvavidyalayam, Tirupati, A.P, INDIA \\ "Corresponding Author e-mail: bsrrgmcet@gmail.com, Tel+91-9440844600,
}

\begin{abstract}
The analysis of functionally graded material (FGM) plates with material variation parameter (n), boundary conditions, aspect ratios and side to thickness ratios are investigated using higher order displacement model. The derivation of equations of motion for higher order displacement model is obtained using principle of virtual work. The nonlinear simultaneous equations are obtained by Navier's method considering certain parameters, loads and boundary conditions. The nonlinear algebraic equations are solved using Newton Raphson iterative method. The numerical results are obtained for various boundary conditions, material variation parameter, aspect ratio, side to thickness ratio and compared with the available solutions. The effect of shear deformation and nonlinearity response of functionally graded material plate is studied.
\end{abstract}

Keywords: Nonlinear analysis, FGM plates, higher order theories, Navier's method, Newton Raphson method.

\section{Introduction}

A functionally graded material (FGM) is a material in which the composition and structure gradually change resulting in a corresponding change in the properties of the material. This FGM concept can be applied to various materials for structural and functional uses (Miyamoto et.al, 1996; Tahani and Mirzababaee, 2009). The behavioral analysis of functionally graded composite materials is an important field of research owing to the interest for a wide range of applications. Because of their superior advantages such as high resistance to temperature gradients, capability to withstand to high loads and high temperature fields and high durable properties, reduction in residual and thermal stresses, high wear resistance, and an increase in strength to weight ratio when compared to the other engineering materials (Akhavan and Hamed, 2010). However, FGM plates under mechanical loading may undergo elastic instability. Hence, the non-linear behavior of functionally graded plates has to be understood for their optimum design. Reddy (2000) proposed the theoretical formulation using Navier's solutions of rectangular plates and finite element models based on shear deformation theory and presented the analysis of through thickness functionally graded plates. Shen (2002) presented nonlinear bending analysis for a simply supported functionally graded rectangular plate subjected to transverse uniform or sinusoidal load. Galerkin technique is employed to determine load deflection and load bending deflection and load bending moments. Ashraf and Zenkour (2006) presented the static response for simply supported functionally graded rectangular plates subjected to a transverse uniform load. The equilibrium equations of a functionally graded plates are given are based on a generalized shear deformation plate theory. The influences based on shear deformation, plate aspect ratio, side to thickness ratio and volume fraction distributions are investigated. Praveen and Reddy (1998) investigated the static response of functionally graded material plates by varying the volume fraction of the ceramic and metallic constituents using a power law distribution and the numerical results for the deflections and stresses are presented. Lee et al. (1989) proposed higher order theory for studying the bending response of functionally graded plates. The Von Karman theory is used for obtaining the approximate solutions for nonlinear bending. Sasaki and Watanabe (1989) developed some techniques for fabricating the FGMs. Fukui and Yamanaka (1992), investigated the effect of the gradation of the composition on the strength and deformation of the thick walled FGM tubes. Birman and Byrd (2007) presented the principal developments in FGMs with an emphasis on the recent work 
published since 2000. Aboudi et al., (2000) provided a detailed review and description of the full generalization of a new Cartesian-coordinate-based higher order theory for functionally graded materials. Aboudi et al., (1999) presented one- and twodirectional versions of the higher order theory. Hirai (1996) studied micro-structural details that are varied by non uniform distribution of the reinforcement phase. Tanigawa (1995) compiled a comprehensive list of papers on the analytical models of thermo elastic behavior of functionally graded materials. Yang et al., (2005) investigated the stochastic bending response of moderately thick FGM plates. The parametric effects of the material gradient property $\mathrm{n}$, boundary conditions, thickness-to-radius ratio and shear deformation on the nonlinear bending of functionally graded plates are investigated for both first order shear deformation theory and third order shear deformation theory (Golmakani and Kadkhodayan, 2010).

The present work is concerned with the determination of nonlinear bending analysis of functionally graded material plates with different geometric parameters, loads and boundary conditions by means of higher order shear deformation model.

\section{Higher- Order Theory for Displacement Model}

Consider a functionally graded rectangular plate made of mixture of metal and ceramics of thickness $h$, side length $a$ in the $x$ direction, and $b$ in the $y$-direction and the location of the rectangular Cartesian coordinate axes used to describe deformations of the plate are given in Figure 1. It is assumed that a state of plane strain exists. Hence, in formulating the higher-order shear deformation theory, a rectangular plate of

$0 \leq \mathrm{x} \leq \mathrm{a} ; 0 \leq \mathrm{y} \leq \mathrm{b}$ and $-\frac{\mathrm{h}}{2} \leq \mathrm{z} \leq \frac{\mathrm{h}}{2}$ is considered.

In order to approximate 3D-elasticity plate problem to a 2D one, the displacement components $u(x, y, z, t), v(x, y, z, t)$ and w (x, $\mathrm{y}, \mathrm{z}, \mathrm{t})$ at any point in the plate are expanded in terms of the thickness coordinate. The displacement field which assumes w $(\mathrm{x}, \mathrm{y}, \mathrm{z})$ constant through the plate thickness is expressed as (Kant, 1988, 1989, 1990, 2001; Pandya, 1988; Marur, 1997; Suresh Kumar et al., 2011):

$$
\left.\begin{array}{l}
\mathrm{u}(\mathrm{x}, \mathrm{y}, \mathrm{z})=\mathrm{u}_{0}(\mathrm{x}, \mathrm{y})+\mathrm{z} \theta_{\mathrm{x}}(\mathrm{x}, \mathrm{y})+\mathrm{z}^{2} \mathrm{u}_{0}{ }^{*}(\mathrm{x}, \mathrm{y})+\mathrm{z}^{3} \theta_{\mathrm{x}}{ }^{*}(\mathrm{x}, \mathrm{y}) \\
\mathrm{v}(\mathrm{x}, \mathrm{y}, \mathrm{z})=\mathrm{v}_{0}(\mathrm{x}, \mathrm{y})+\mathrm{z} \theta_{\mathrm{y}}(\mathrm{x}, \mathrm{y})+\mathrm{z}^{2} \mathrm{v}_{0}{ }^{*}(\mathrm{x}, \mathrm{y})+\mathrm{z}^{3} \theta_{\mathrm{y}}{ }^{*}(\mathrm{x}, \mathrm{y}) \\
\mathrm{w}(\mathrm{x}, \mathrm{y}, \mathrm{z})=\mathrm{w}_{0}(\mathrm{x}, \mathrm{y})+\mathrm{z} \theta_{\mathrm{z}}(\mathrm{x}, \mathrm{y})+\mathrm{z}^{2} \mathrm{w}_{0}{ }^{*}(\mathrm{x}, \mathrm{y})+\mathrm{z}^{3} \theta_{\mathrm{z}}{ }^{*}(\mathrm{x}, \mathrm{y})
\end{array}\right\}
$$

Where $\mathrm{u}_{0}, \mathrm{v}_{0}$ are the in plane displacements of a point $(\mathrm{x}, \mathrm{y})$ on the mid point.

$\mathrm{w}_{0}$ is the transverse displacement of a point $(\mathrm{x}, \mathrm{y})$ on the mid plane.

$\theta_{\mathrm{x}}, \theta_{\mathrm{y}}, \theta_{\mathrm{z}}$ are rotations of the normal to the mid plane about $\mathrm{y}$ and $\mathrm{x}$-axes.

$\mathrm{u}_{0}{ }^{*}, \mathrm{v}_{0}{ }^{*}, \mathrm{w}_{0}{ }^{*}, \theta_{\mathrm{x}}{ }^{*}, \theta_{\mathrm{y}}{ }^{*}$, and $\theta_{\mathrm{z}}{ }^{*}$ are the corresponding higher order deformation terms

All the generalized displacements $\left(\mathrm{u}_{0}, \mathrm{v}_{0}, \mathrm{w}_{0}, \theta_{\mathrm{x}}, \theta_{\mathrm{y}}, \theta_{\mathrm{Z}}\right)$ are functions of $\mathrm{x}, \mathrm{y}$ and $\mathrm{Z}$. In the present work, analytical formulation and solutions are obtained without enforcing zero transverse shear stress conditions on the top and bottom surfaces of the plate.

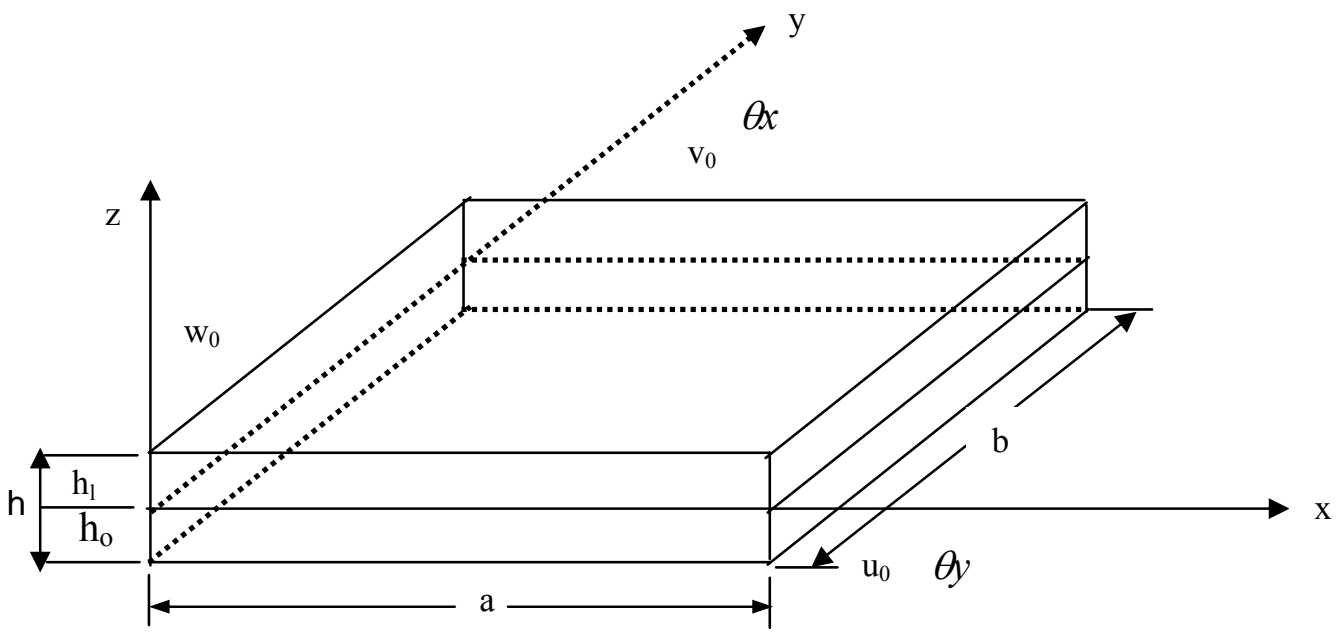

Figure.1. FGM Geometry with reference axes, displacement components. 
From strain-displacement relations appropriate for infinitesimal deformations, the following relations are obtained as:

2.1. Constitutive Relations

The variation of material properties of a FGM plate can be expressed as:

$$
\mathrm{P}(\mathrm{Z})=\left(\mathrm{P}_{\mathrm{t}}-\mathrm{P}_{\mathrm{b}}\right) \mathrm{V}+\mathrm{P}_{\mathrm{b}}
$$

Where $P$ denotes material property like modulus, $P_{t}$ and $P_{b}$ denotes the corresponding properties of the top and bottom faces of the plate, respectively, and $n$ is a parameter that dictates the material variation profile through the thickness. Also $V$ in Eq. (2) denotes the volume fraction of the top face constituent and follows a simple power-law as:

$$
\mathrm{V}=\left(\frac{\mathrm{Z}}{\mathrm{h}}+\frac{1}{2}\right)^{\mathrm{n}}
$$

Where $h$ is the total thickness of the plate, $z$ is the thickness coordinate and $n$ is a parameter that dictates the material variation profile through the thickness. Here it is assumed that moduli E and G vary according to Eq. (2) and the Poisson's ratio $v$ is assumed to be a constant. The linear constitutive relations are:

$$
\begin{aligned}
& \left\{\begin{array}{c}
\sigma_{\mathrm{x}} \\
\sigma_{\mathrm{y}} \\
\sigma_{\mathrm{z}} \\
\tau_{\mathrm{xy}} \\
\tau_{\mathrm{yz}} \\
\tau_{\mathrm{xz}}
\end{array}\right\}=\left[\begin{array}{llllll}
\mathrm{Q}_{11} & \mathrm{Q}_{12} & \mathrm{Q}_{13} & 0 & 0 & 0 \\
\mathrm{Q}_{12} & \mathrm{Q}_{22} & \mathrm{Q}_{23} & 0 & 0 & 0 \\
\mathrm{Q}_{13} & \mathrm{Q}_{23} & \mathrm{Q}_{33} & 0 & 0 & 0 \\
0 & 0 & 0 & \mathrm{Q}_{44} & 0 & 0 \\
0 & 0 & 0 & 0 & \mathrm{Q}_{55} & 0 \\
0 & 0 & 0 & 0 & 0 & \mathrm{Q}_{66}
\end{array}\right]\left\{\begin{array}{c}
\varepsilon_{\mathrm{x}} \\
\varepsilon_{\mathrm{y}} \\
\varepsilon_{\mathrm{z}} \\
\gamma_{\mathrm{xy}} \\
\gamma_{\mathrm{yz}} \\
\gamma_{\mathrm{zx}}
\end{array}\right\} \\
& \text { Where } \quad \sigma=\left(\sigma_{\mathrm{X}}, \sigma_{\mathrm{Y}}, \sigma_{\mathrm{Z}} \tau_{\mathrm{XY}}, \tau_{\mathrm{YZ}}, \tau_{\mathrm{XZ}}\right)^{\mathrm{T}} \text { are the stresses } \\
& \varepsilon=\left(\varepsilon_{\mathrm{x}}, \varepsilon_{\mathrm{y}}, \varepsilon_{\mathrm{z}} \gamma_{\mathrm{xy}}, \gamma_{\mathrm{yz}}, \gamma_{\mathrm{xz}}\right)^{\mathrm{t}} \text { are the strains }
\end{aligned}
$$

$\mathrm{Q}_{\mathrm{ij}} \mathrm{S}$ are the plane stress reduced elastic constants in the plate axes. The superscript $\mathrm{t}$ denotes the transpose of a matrix.

\section{2. Equations of Motion}

The governing equations of displacement model in Eq. (1) are derived using the dynamic version of the principle of virtual displacements, i.e.

$$
\left.\int_{0}^{\mathrm{T}} \delta \mathrm{u}+\delta \mathrm{v}-\delta \mathrm{k}\right) \mathrm{dt}=0
$$

where $\quad \delta u=$ virtual strain energy

$$
\begin{aligned}
& \delta \mathrm{v}=\text { virtual work done by applied forces } \\
& \delta \mathrm{k}=\text { virtual kinetic energy } \\
& \delta \mathrm{u}+\delta \mathrm{v}=\text { total potential energy. }
\end{aligned}
$$

the virtual strain energy, work done and kinetic energy are given by:

$$
\begin{aligned}
& \delta \mathrm{u}=\int_{\mathrm{A}}\left\{\int_{-h / 2}^{h / 2}\left[\sigma_{\mathrm{x}} \delta \varepsilon_{\mathrm{x}}+\sigma_{\mathrm{y}} \delta \varepsilon \mathrm{y}+\tau_{\mathrm{xy}} \delta \gamma_{\mathrm{xy}}+\tau_{\mathrm{xz}} \delta \gamma_{\mathrm{xz}}+\tau_{\mathrm{xy}} \delta \gamma_{\mathrm{xy}} \tau_{\mathrm{yz}} \delta \gamma_{\mathrm{yz}}\right] \mathrm{dz}\right\} \mathrm{dxdy} \\
& \delta \mathrm{v}=-\int \mathrm{q} \delta \mathrm{w}_{0} \mathrm{dxdy} \\
& \delta \mathrm{K}=\int_{\mathrm{A}}\left\{\begin{array}{l}
\mathrm{h} / 2 \rho_{0}\left[\left(\dot{\mathrm{u}}_{0}+\mathrm{Z} \dot{\theta}_{\mathrm{x}}+\mathrm{Z}^{2} \dot{\mathrm{u}}_{0}{ }^{*}+\mathrm{Z}^{3} \dot{\theta}_{\mathrm{x}}{ }^{*}\right)\left(\delta \dot{\mathrm{u}}_{0}+\mathrm{Z} \delta \dot{\theta}_{\mathrm{x}}+\mathrm{Z}^{2}{ }_{\delta} \dot{\mathrm{u}}_{0}{ }^{*}+\mathrm{Z}^{3} \dot{\theta}_{\mathrm{x}}{ }^{*}\right)\right. \\
\left.-\mathrm{h} / 2+\left(\dot{\mathrm{v}}_{0}+\mathrm{Z} \dot{\theta}_{\mathrm{y}}+\mathrm{Z}^{2} \dot{\mathrm{v}}_{0}{ }^{*}+\mathrm{Z}^{3} \dot{\theta}_{\mathrm{y}}{ }^{*}\right)\left(\delta \dot{\mathrm{v}}_{0}+\mathrm{Z} \delta \dot{\theta}_{\mathrm{y}}+\mathrm{Z}^{2} \dot{\mathrm{v}}_{0}{ }^{*}+\mathrm{Z}^{3} \delta \dot{\theta}_{\mathrm{y}}{ }^{*}\right)+\dot{\mathrm{w}}_{0} \delta \dot{\mathrm{w}}_{0}\right] \mathrm{dz}
\end{array}\right\} \mathrm{dxdy}
\end{aligned}
$$

where $\mathrm{q}=$ distributed load over the surface of the functionally graded plate. $\rho_{0}=$ density of plate material

$$
\dot{u}_{0}=\partial \mathrm{u}_{0} / \partial \mathrm{t}, \dot{v}_{0}=\partial \mathrm{v}_{0} / \partial \mathrm{t} \text { etc. indicates the time derivatives }
$$

Substituting $\delta \mathrm{u}, \delta \mathrm{v}$ and $\delta \mathrm{k}$ from Eq. (6-8) into the virtual work statement in Eq. (5) and integrating through the thickness of the functionally graded plate, the in-plane, transverse force and moment resultant relations are obtained. Substituting Eq. (4) into force and moment resultants and upon integration the expressions obtained and written in a matrix form which defines the stress / strain relations of the FGM plate is given by: 


$$
\left\{\begin{array}{l}
\mathrm{N} \\
\mathrm{N}^{*} \\
-- \\
\mathrm{M} \\
\mathrm{M}^{*} \\
-- \\
\mathrm{Q} \\
\mathrm{Q}^{*}
\end{array}\right\}=\left[\begin{array}{c|ccc}
\frac{\mathrm{A}}{\mathrm{B}^{\mathrm{t}}} & \frac{\mathrm{B}}{\overline{\mathrm{D}_{\mathrm{b}}}} \mid & \frac{0}{0} \\
\overline{0} & \overline{0} & \overline{\mathrm{D}_{\mathrm{S}}}
\end{array}\right]\left\{\begin{array}{l}
\varepsilon_{0} \\
* \\
\varepsilon_{0} \\
-- \\
\mathrm{K}_{\mathrm{S}} \\
\mathrm{K}^{*} \\
-- \\
\theta \\
\theta^{*}
\end{array}\right\}
$$

The principle of virtual work is used to derive the equilibrium equations and are expressed in terms of $\mathrm{u}_{\mathrm{o}}, \mathrm{v}_{\mathrm{o}}, \mathrm{w}_{\mathrm{o}}, \theta_{\mathrm{x}}, \theta_{\mathrm{y}}, \theta \mathrm{z}, \mathrm{u}_{\mathrm{o}}{ }^{*}, \mathrm{v}_{\mathrm{o}}{ }^{*}$, $\mathrm{w}_{0}{ }^{*}, \theta_{\mathrm{x}}{ }^{*}, \theta_{\mathrm{y}}{ }^{*}, \theta_{\mathrm{z}}{ }^{*}$ by substituting for the force and moment resultant from eq.(9).

\section{Analysis of functionally graded material plate using displacement model}

The simply supported (SS) boundary conditions are considered for displacement model. The Navier solution procedure, displacement components that satisfy the equations of boundary conditions are considered for the analysis. The Solutions are obtained using Newton Raphson method.

3.1 Newton Raphson Method for nonlinear analysis: The Newton Raphson iterative method is based on Taylor's series expansion. In the present work, the equation $\left[\mathrm{S}\left(\Delta_{\mathrm{s}+1}\right)\right]\{\Delta\}_{\mathrm{s}+1}=\{\mathrm{F}\}$ is solved for generalized displacement vector $\left.\{\Delta\}\right\}_{\mathrm{s}+1}$ by Newton Raphson iterative method.

The iterative procedure is as follows:

$$
\{\mathrm{R}\}\left\{\{\Delta\}_{\mathrm{s}+1}\right\}=\left[\mathrm{S}\left(\Delta_{\mathrm{s}+1}\right)\right]\{\Delta\}_{\mathrm{s}+1}-\{\mathrm{F}\}
$$

$\mathrm{R}$ is called Residual and $\left[\mathrm{S}\left(\Delta_{\mathrm{s}+1}\right)\right]$ is the stiffness matrix, which is a function of the unknown deflections $\{\Delta\}_{\mathrm{s}+1}$.

Expanding $\{\mathrm{R}\}$ in Taylor series about $\{\Delta\}^{\mathrm{r}}{ }_{\mathrm{s}+1}$

$$
\{0\}=\{\mathrm{R}\}_{\mathrm{s}+1}+\left[\mathrm{K}^{\mathrm{T}}\left(\{\Delta\}_{\mathrm{s}+1}^{\mathrm{r}}\right)\right]\{\delta \Delta\}+\mathrm{O}\left(\{\delta \Delta\}^{2}\right)
$$

Where $\mathrm{O}\left(\right.$.) denotes the higher-order terms in $\{\delta \Delta\}$, and $\left[\mathrm{K}^{\mathrm{T}}\right]$ is known as the tangent stiffness matrix (geometric stiffness matrix)

$$
\{\mathrm{R}\}_{\mathrm{s}+1}^{\mathrm{r}}=\left[\mathrm{K}\left(\Delta_{\mathrm{s}+1}^{\mathrm{r}}\right)\right]\{\Delta\}^{\mathrm{r}}{ }_{\mathrm{s}+1-} \cdot\{\mathrm{F}\}
$$

The assembled equations are then solved for incremental displacement vector after imposing the boundary and conditions of the problem

$$
\begin{aligned}
& \{\delta \Delta\}=-\left[\mathrm{K}^{\mathrm{T}}\left(\{\Delta\}^{\mathrm{r}}{ }_{\mathrm{s}+1}\right)\right]^{-1}\{\mathrm{R}\}^{\mathrm{r}}{ }_{\mathrm{s}+1} \\
& \{\Delta\}^{\mathrm{r}+1}{ }_{\mathrm{s}+1}=\{\Delta\}^{\mathrm{r}}{ }_{\mathrm{s}+1}+\{\delta \Delta\}
\end{aligned}
$$

Total displacement vector is obtained from the tangent stiffness matrix, using the latest known solution and the process will continue until the termination criteria with a pre-selected error tolerance is obtained.

\section{Results and discussions}

The Navier solutions are developed for rectangular plates with two sets of simply supported (SS) boundary conditions. The two types of boundary conditions are given below.

The SS boundary conditions are:

At edges $\mathrm{x}=0$ and $\mathrm{x}=\mathrm{a}$

$$
\begin{aligned}
& \mathrm{v}_{0}=0, \mathrm{w}_{\mathrm{o}}=0, \theta_{\mathrm{y}}=0, \theta_{\mathrm{z}}=0, \mathrm{M}_{\mathrm{x}}=0, \mathrm{v}_{0}{ }^{*}=0, \mathrm{w}_{0}{ }^{*}=0, \\
& \theta_{\mathrm{y}}{ }^{*}=0, \theta_{\mathrm{z}}{ }^{*}=0, \mathrm{M}_{\mathrm{x}}{ }^{*}=0, \mathrm{~N}_{\mathrm{x}}=0, \mathrm{~N}_{\mathrm{x}}{ }^{*}=0 .
\end{aligned}
$$

At edges $\mathrm{y}=0$ and $\mathrm{y}=\mathrm{b}$

$$
\begin{aligned}
& \mathrm{u}_{0}=0, \mathrm{w}_{\mathrm{o}}=0, \theta_{\mathrm{x}}=0, \theta_{\mathrm{z}}=0, \mathrm{M}_{\mathrm{y}}=0, \mathrm{u}_{0}{ }^{*}=0, \mathrm{w}_{0}{ }^{*}=0, \\
& \theta_{\mathrm{x}}{ }^{*}=0, \theta_{\mathrm{z}}{ }^{*}=0, \mathrm{M}_{\mathrm{y}}{ }^{*}=0, \mathrm{~N}_{\mathrm{y}}=0, \mathrm{~N}_{\mathrm{y}}{ }^{*}=0 .
\end{aligned}
$$

In order to verify the accuracy and efficiency of the developed theories results and to study the effects of transverse shear deformation, the following typical material properties are used for obtaining the numerical results.

\section{Material 1:(Aluminium)}

$$
\mathrm{E}=70 \mathrm{GPa} ; \mathrm{v}=0.3, \rho=2,707 \mathrm{Kg} / \mathrm{m}^{3}, \kappa=204 \mathrm{~W} / \mathrm{mK}, \alpha=23 \times 10^{-6} /{ }^{0} \mathrm{C}
$$

\section{Material 2:(Zirconia)}

$$
\mathrm{E}=151 \mathrm{GPa} ; \mathrm{v}=0.3, \rho=3,000 \mathrm{Kg} / \mathrm{m}^{3}, \kappa=209 \mathrm{~W} / \mathrm{mK}, \alpha=10 \times 10^{-6} /{ }^{0} \mathrm{C}
$$


The center deflection is presented here in non-dimensional form using the following.

$$
\overline{\mathrm{w}}=\frac{\mathrm{w}_{0}}{\mathrm{~h}}
$$

The solution procedures outlined in the previous section are applied to functionally graded simply supported square plate subjected to transverse load. The material properties adopted here and non-dimensionalzed parameters used are presented. The nonlinear results obtained using higher order theory are compared with the available literature (Matsunaga, 2009; Zenkour, 2005 and 2006; Ferria, 2005; Mechab, 2010; Qian, 2004; Reddy, 2000) and shown in Figure 2-9.

Figure 2 and Figure 3 represents the central deflections of the square simply supported FGM plate with different side to thickness ratio's against the power law index. From the Figure 2 and Figure 3 it is seen that, the present results are very close agreement with the Zenkour, 2006; Ferria, 2005; Qian, 2004 ; Matsunaga, 2009; Reddy, 2000, Mechab, 2010 results. It can also be seen that, as the power law index increases, the nondimensonal center deflection difference increases. It can also be observed that, the central deflection difference increases with the increase of side to thickness ratio's and decrease of aspect ratios. From Figure 4 and Figure 5 is clear that, as the power law index increases, the normal stress $\left(\sigma_{\mathrm{x}}\right)$ and $\left(\sigma_{\mathrm{y}}\right)$ decreases as the power law index increases (Reddy, 2000; Zenkour, 2006).

Fig 6-9 shows the variation of normal stresses and transverse shear stresses with different aspect ratios and side to thickness ratios. From the Fig 6-9, it is concluded that, the shear stress and normal stress $\left(\sigma_{\mathrm{y}}\right)$ increases as the power law index, side to thickness ratio and aspect ratio increases and decreases the normal stress $\left(\sigma_{y}\right)$ with the increase of power law index and aspect ratio.

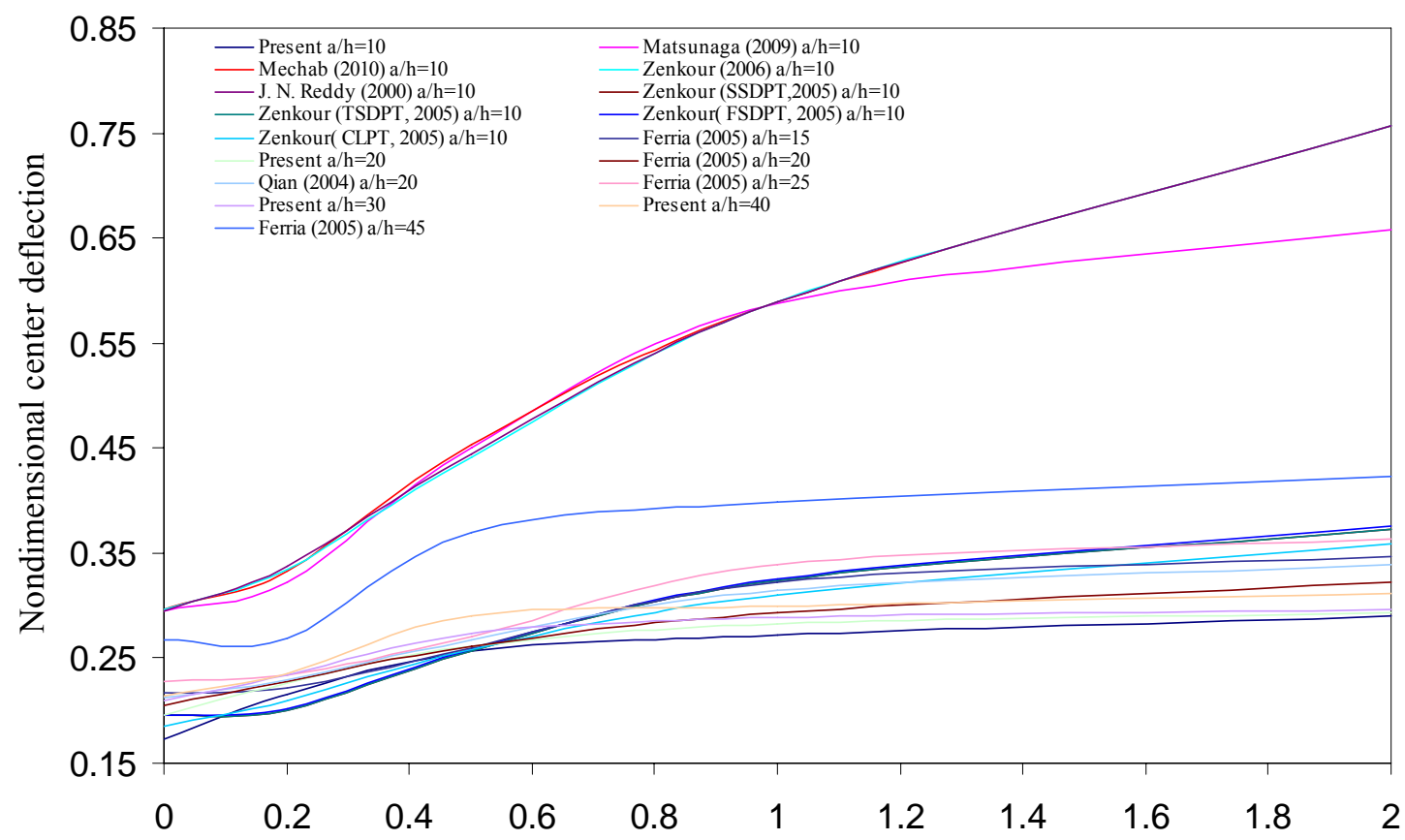

Power law index $n$

Figure.2: Non-dimensionalized center deflection (w) Vs Power law index (n) with different side to thickness ratio's for a simply supported FGM plate 


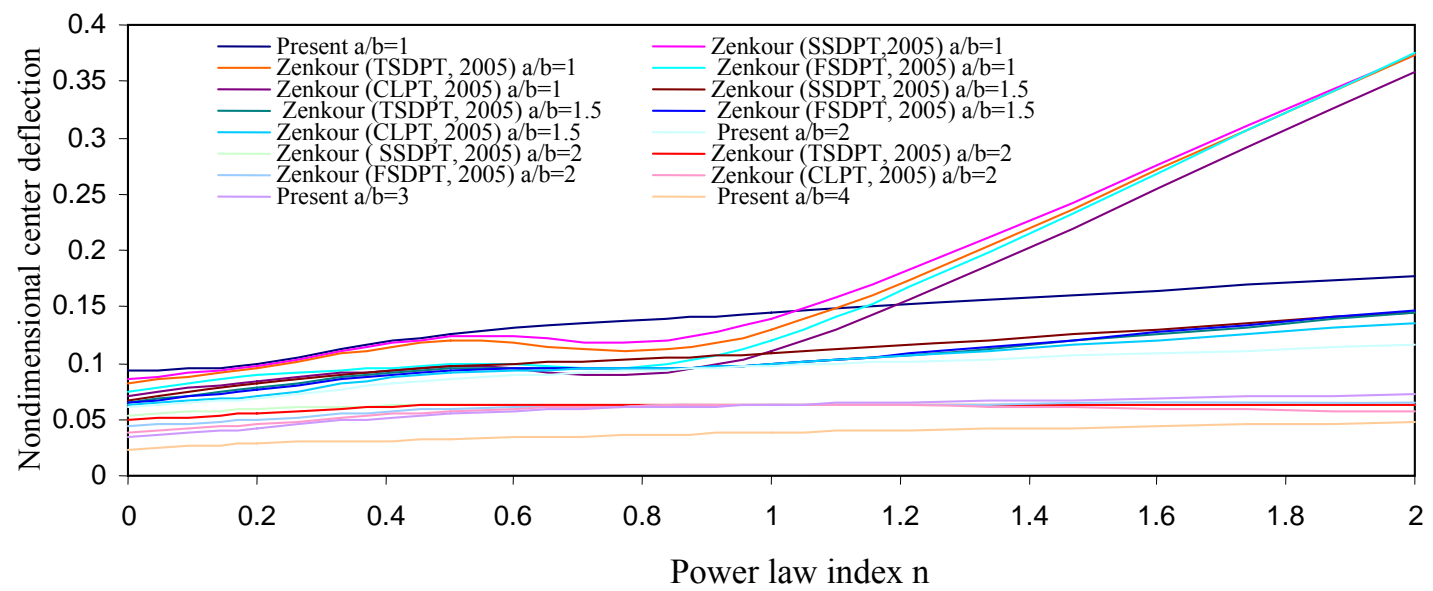

Figure 3: Non-dimensionalized center displacement Vs power law index (n) with different aspect ratios (a/b) for a simply supported FGM plate

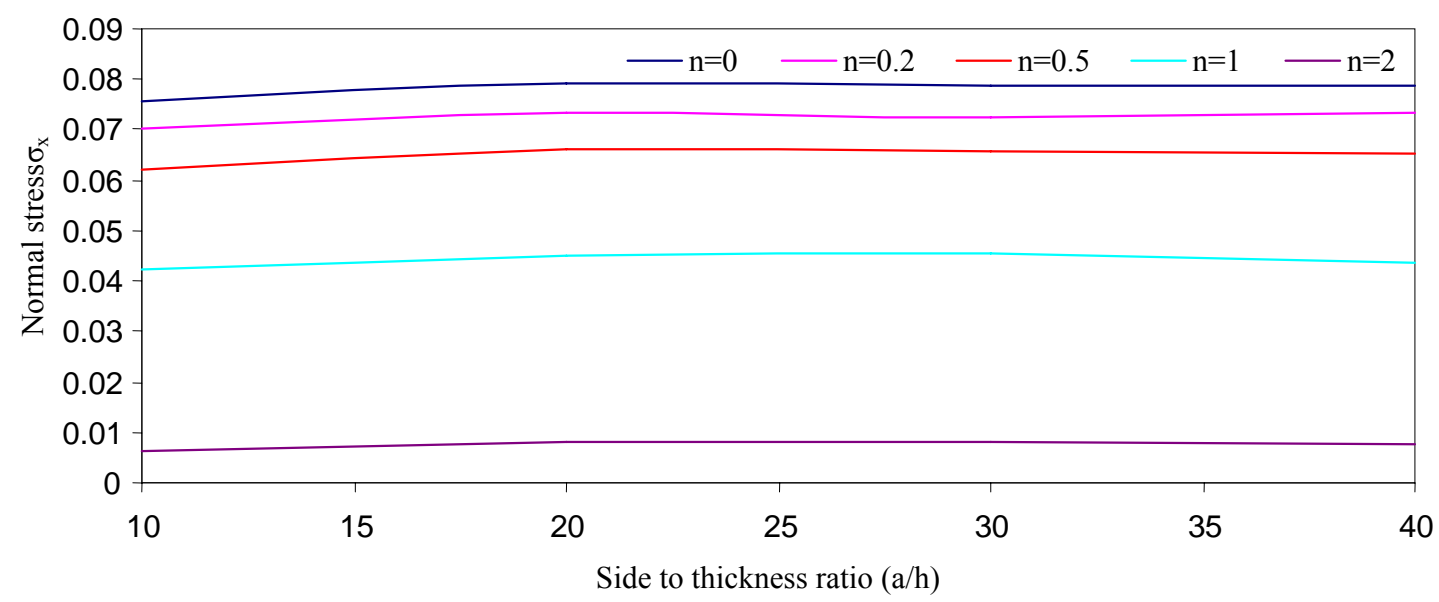

Figure 4: Non-dimensionalized normal stress $\left(\sigma_{\mathrm{x}}\right)$ Vs Side to thickness ratio $(\mathrm{a} / \mathrm{h})$ for a simply supported FGM plate

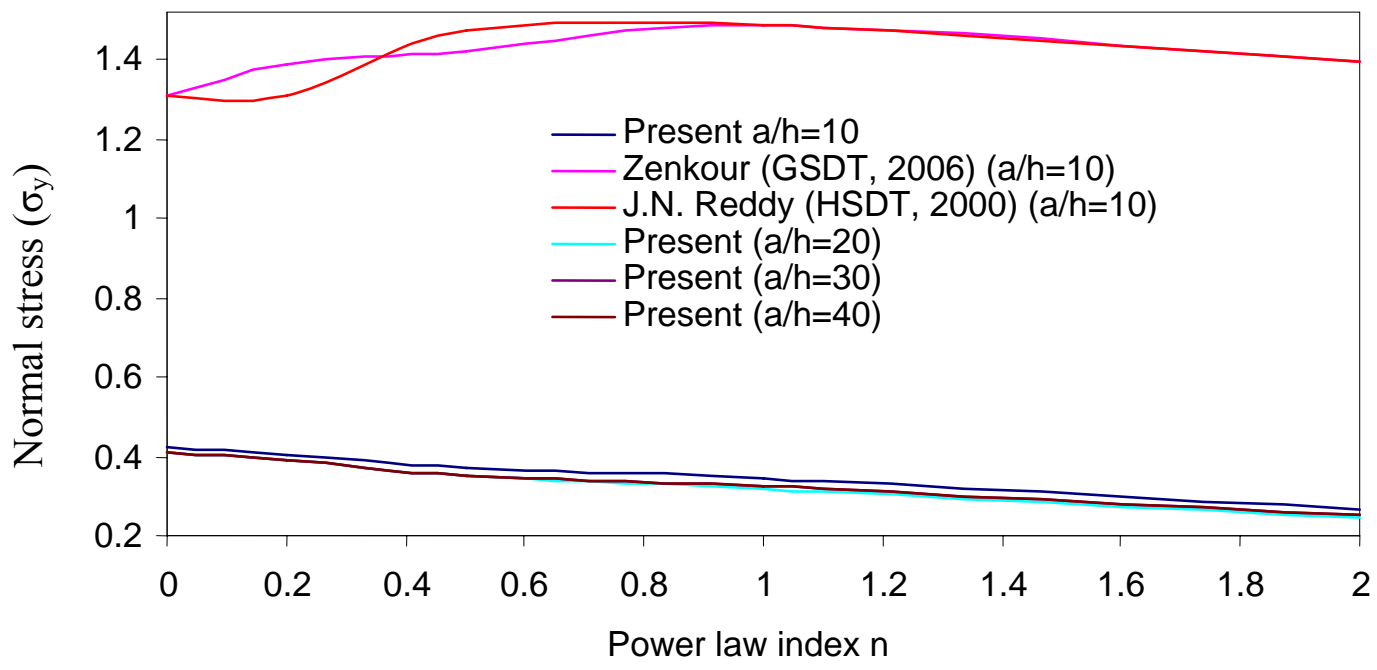

Figure. 5: Non-dimensionalized normal stress $\left(\sigma_{y}\right)$ Vs power law index (n) with different side to thickness ratio's for a simply supported FGM plate 


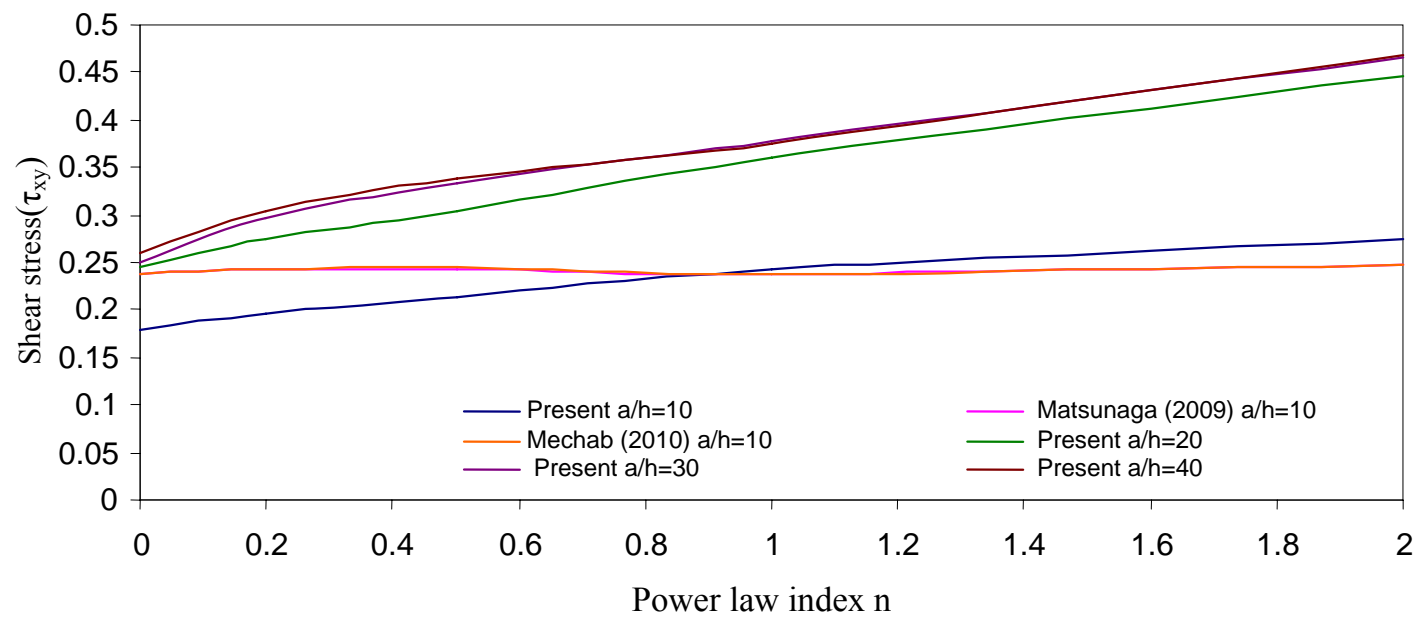

Figure 6: Non-dimensionalized shear stress $\left(\tau_{\mathrm{xy}}\right)$ Vs power law index with different Side to thickness ratio (a/h) for a simply supported FGM plate

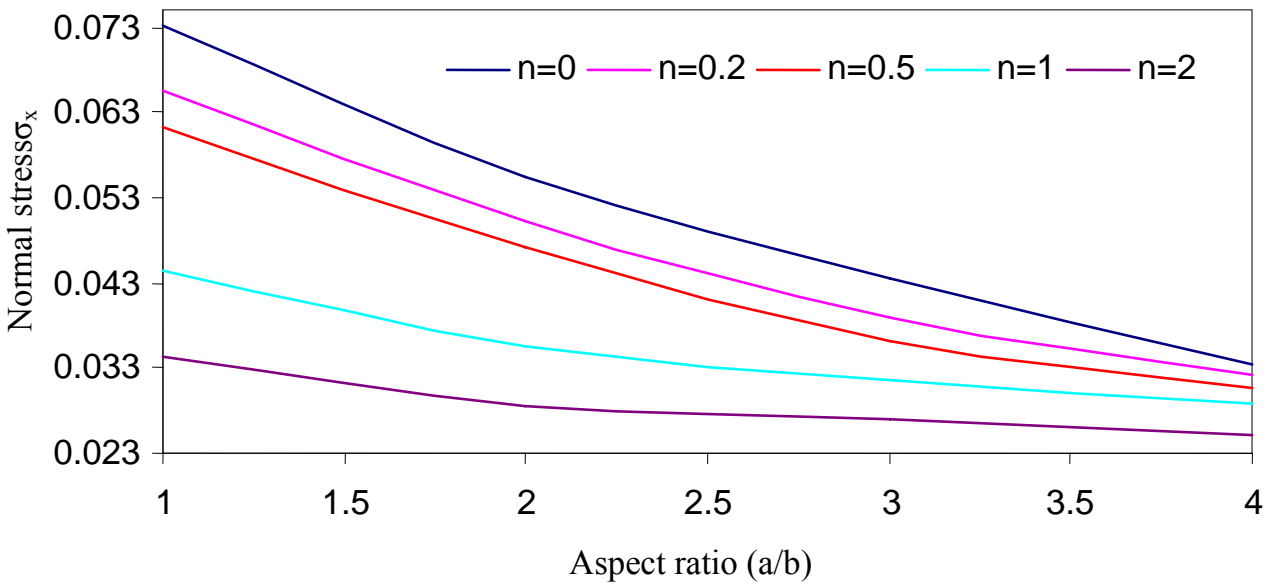

Figure 7: Non-dimensionalized normal stress $\left(\sigma_{\mathrm{x}}\right)$ Vs Aspect ratio $(\mathrm{a} / \mathrm{b})$ for a simply supported FGM plate for displacement model

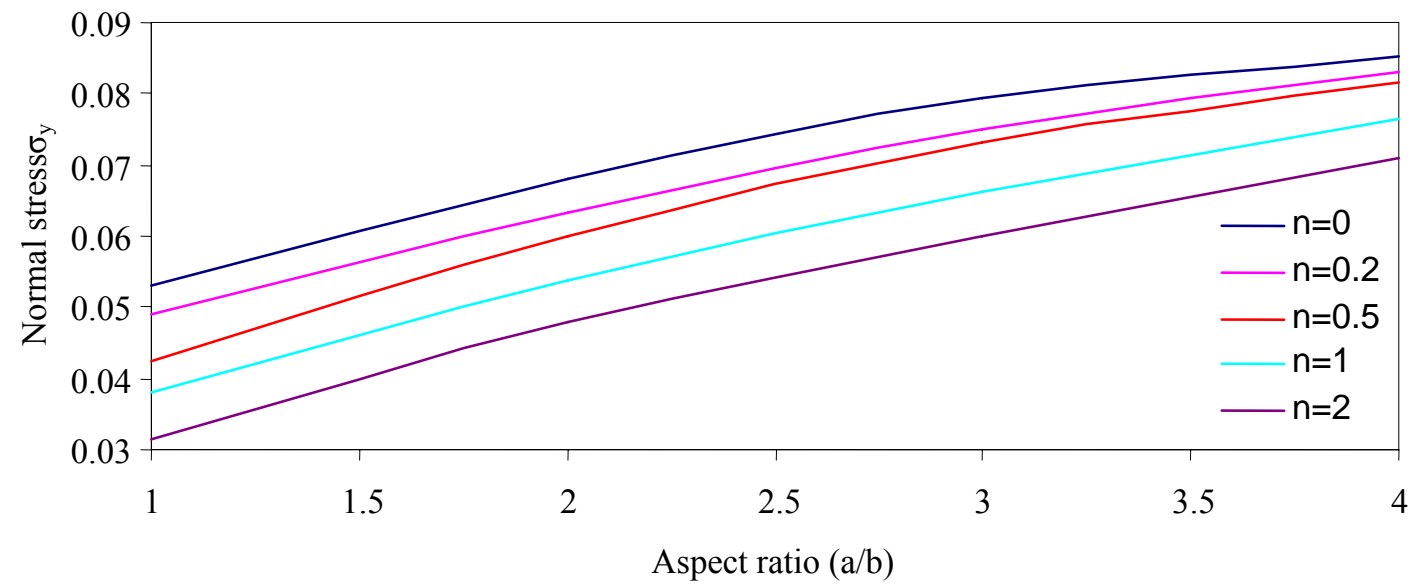

Figure 8: Non-dimensionalized normal stress $\left(\sigma_{\mathrm{y}}\right)$ Vs Aspect ratio $(\mathrm{a} / \mathrm{b})$ for a simply supported FGM plate for displacement model 


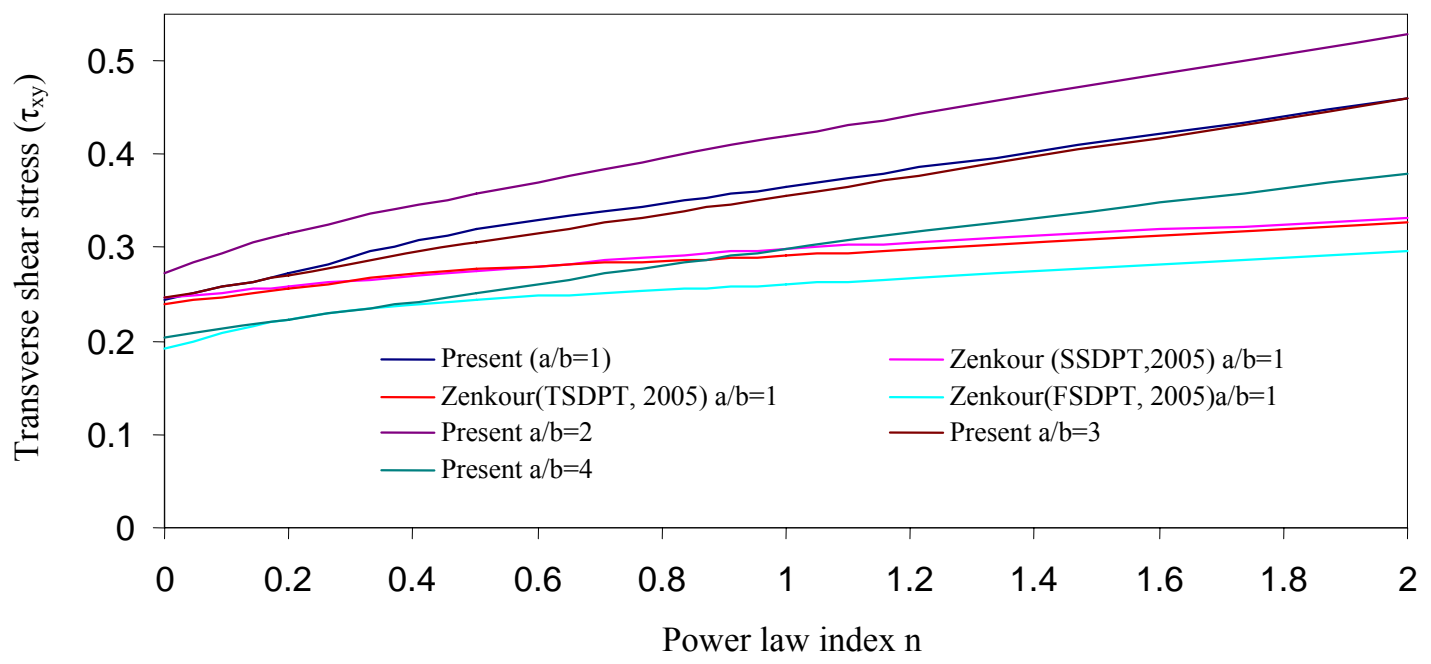

Figure 9: Non-dimensionalized shear stress $\left(\tau_{\mathrm{xy}}\right)$ Vs Power law index $(\mathrm{n})$ with different aspect ratio $(\mathrm{a} / \mathrm{b})$ for a simply supported FGM plate

\section{Conclusions}

The following conclusions are drawn from the results for functionally gradient material plates:

1) The effect of nonlinearity in functionally graded composite plates is to decrease the central deflections with increase of side to thickness ratio. This effect is found to be more predominant in decreasing the deflections in thin plates for side to thickness ratio of 10 .

2) The effects of geometric nonlinearity is to decrease the transverse shear stresses, transverse normal stresses with increase in side to thickness ratio, when compared to linear analysis, due to the consideration of Von-Karman strains in straindisplacement relations, but the shear stresses increases with increase in side to thickness ratio. The central deflections, normal stresses $\sigma_{x}$, shear stresses $\tau_{x y}$ decrease with increase of aspect ratio whereas normal stress $\sigma_{y}$ increases with the increase of aspect ratio.

The developed theories in this paper can be extended to include thermal procedures in determining the thermal effects on the functionally graded materials and also for problems of shells. The soft computing techniques namely, genetic algorithms, neural networks, particle swarm optimization etc. can be employed for the analysis and better utilization of functionally graded material plates. The study of thermal bending effects along with bending thermal effects on FGMs will be more purposeful as these materials are used in the applications where materials with combined properties like resistant to temperatures and ability to with stand loads are needed.

\section{References}

Aboudi. J, Pindera, M.J.; and Arnold, S.M. 1999. Higher-order theory for functionally graded materials. Composites Part B-Engineering, Vol. 30, No. 8, pp. 777-832.

Aboudi, J.; Pindera M.J., and Arnold S.M., 2000. Higher-Order Theory for Functionally Graded Materials, June..

Akhavan, H. 2010. April 7. Functionally Graded Plates. SciTopics. Retrieved September 3, 2010.

Birman V., Byrd L.W.. 2007. Modeling and analysis of functionally graded materials and structures, Applied Mechanics Reviews, Vol. 60, No. 5, pp.195-216.

Ferreira A.J.M, Batra R.C, Roque, C.M.C, Qian, L.F and Martins, P.A.L.S, 20065. Static analysis of functionally graded plates using third order shear deformation theory and a meshless method. International Journal of Composite Structures, Vol. 69, pp. 449-457.

Fukui Y, Yamanaka N. 1992. Elastic analysis for thick-walled tubes of FGM subjected to internal pressure. Int J Japan Soc Mech Eng Ser A, Vol. 35, pp. 379-385.

Golmakani ME, Kadkhodayan M. 2010. Nonlinear bending analysis of annular FGM plates using higher-order shear deformation plate theories. Compos Struct., doi:10.1016/j.compstruct.2010.06.024

Hirai, T.: 1996. Functional Gradient Materials. Processing of Ceramics, pt. 2, vol. 17B, Richard J. Brook, et al., eds., Weinheim, New York, NY., pp. 293-341. 
Kant. T, Manjunath B.S., 1990. Higher order theories for symmetric and unsymmetric fibre reinforced composite beams with $\mathrm{C}^{0}$ finite elements, J. of Finite Elements in Analysis and Design, Vol. 6, pp. 303-330.

Kant. T, and Mallikarjuna, 1989. A higher-order theory for free vibration of unsymmetrically laminated composite and sandwich plate finite element evaluations, Journal of Computers and Structures, Vol. 32, No.5., pp. 1125-1132.

Kant. T, Swaminathan K., 2001. Analytical solutions for free vibration of laminated composites and sandwitch plates based on higher order refined theory. J. of Composite Structures, Vol. 53, pp. 73-85.

Kant. T, Pandya B. N., 1988. A simple finite element formulation of a higher-order theory for unsymmetrically laminated composite plates, Journal of Composite Structures, Vol. 9, pp. 215-246.

Lee K.H., Senthilnathan N.R, Lim S.P, and Chow S.T., 1989. Nonlinear bending response of functionally graded plates subjected to transverse loads and in thermal environments. International Journal of Non-Linear Mechanics. Vol. 24, No. 2, pp. 127-137.

Matsunaga, H. 2009. Stress analysis of functionally graded plates subjected to thermal and mechanical loadings, Internatioal Journal of Composite Structures, Vol. 87, pp.344-357.

Marur. S.R., Kant T., 1997. On the performance of higher order theories for transient dynamic analysis of sandwitch and composite beams, Journal of Composites and Structures, Vol. 65. No.5, pp. 741-759.

Mechab I., Atmane H.A., Tounsi A., Belhadj H.A., Bedia E.A., 2010. A two-variable refined plate theory for the bending analysis of functionally graded plates. International Journal of Acta Mech Sim, Vol. 26, pp.941-949.

Miyamoto. Y, M.Niino and M.Koizumi, 1996. FGM research programs in Japan-from structural to functional uses, Proceedings of the $4^{\text {th }}$ International Symposium on Functionally Graded Materials, AIST Tsukuba Research Center, Tsukuba, Japan, October 21-24, pp. 1-8.

Pandya. B. N, \& Kant T., 1998. Finite element analysis of laminated composite plates using a higher-order displacement model, Journal. Composites Science and Technology, Vol. 32, pp. 137-155.

Praveen G.N. and Reddy.J.N., 1998. A simple higher-order non-linear shear deformation plate theory. International Journal of Solids and Structures. Vol. 35, No. 33, pp. 4457-4476.

Qian, L.F, Batra, R.C, Chen, L.M. 2004. Static and dynamic deformations of thick functionally graded elastic plate by using higher order shear and normal deformable plate theory and meshless local Petrov-Galerkin method. International Journal of Composites Part B Engineering, Vol.35, No. 6-8, pp. 685-697.

Reddy, J.N., 2000. Analysis of functionally graded plates. International Journal for Numerical Methods in Engineering, Vol. 47, No. 1-3, pp.663-684.

Sasaki M, Wang y, Hirano T,hirai T. 1989. Design of SiC/C FGM and its propagation by chemical vapour deposition. J. Ceramic Soc Japan, Vol. 97, No. 5, pp. 539-543.

Shen H.-S., 2002. Generalized shear deformation theory for bending analysis of functionally graded plates. International Journal of Mechanical Sciences,.Vol. 44, No. 3, pp. 561-584.

Suresh Kumar J, Reddy B. S. and Reddy C.E., 2011. Nonlinear bending analysis of functionally graded plates using higher order theory, International Journal of Engineering Science and Technology, Vol. 3, No. 4, pp. 1310-1322.

Tanigawa Y. 1995. Some basic thermoelastic problems for non homogeneous structural materials. Applied Mechanical Review, Vol. 48, pp. 377-389.

Tahani M., Mirzababaee S.M., 2009. Non-linear analysis of functionally graded plates in cylindrical bending under thermomechanical loadings based on a layerwise theory, European Journal of Mechanics A/Solids, Vol. 28, pp. 248-256.

Yang. J, Liew K.M. and Kitipornchai S., 2005. Stochastic analysis of compositionally graded plates with system randomness under static loading, International Journal of Mechanical Sciences, Vol. 47, pp. 1519-1541.

Zenkour A.M., 2006. Generalized shear deformation theory for bending analysis of functionally graded plates. Applied Mathematical Modeling. Vol. 30, No. 1, pp. 67-84.

Zenkour A.M., 2005. A comprehensive analysis of functionally graded sandwich pates: part 1-Deflectiona and stresses, International Journal of Solids and Structures, Vol. 42, pp. 5224-5242.

\section{Biographical notes}

Dr. J. Suresh Kumar is currently working as Associate Professor in Mechanical Engineering in Jawaharlal Nehru Technological University, Hyderabad. He completed his Masters in 1995 and did his Ph.D from JNTU College of Engineering, Kakinada in 2005. He has presented / Published 25 papers in Various National \& International Conferences / Journals. He has organized 3 National level conferences \& short term courses. He is a life member of I.S.T.E. He worked as Erection and Plant engineer at Golden Agro- Tech Industries Ltd during 1992-1996. His areas of interests are Alternative fuels \& CFD, Optimization techniques, soft computing and Composite structures.

Mr. B. Sidda Reddy, obtained his Masters Degree from S.V University, Tirupati in 2007.He is working as Assistant Professor in the Department of Mechanical Engineering in R.G.M College of Engg. \& Tech.Nandyal, Andhra Pradesh Since 2005.He has presented 09 papers in National and International Conferences, 07 papers has published in National Journal and 08 papers has published in International Journal. His areas of interests are I.C Engines, Alternative fuels \& CFD, Optimization techniques, soft computing.

Dr. C. Eswara Reddy, is graduated in 1977, Masters in 1983 and did his Ph.D from Indian Institute of Technology, Madraas in 1992. He guided 8 Ph.D students and another $15 \mathrm{Ph}$. D scholars doing their research under his guidance. He has presented and published 120 papers in Various National \& International 
Conferences/journals. He has organized 13 national level conferences \& short term courses and attended 21 National workshops.. He had the much administrative experience in S.V.Universiy.He is the member of Executive committee, ISTE, AP Chapter, Hyderabad, Executive member, ISTE Chapter-2009-2010, student member, International Society for Auto \& Robotics, Hong Kong, (upto 1994), Life member, Fellow, Institution of Engineers (India), Calcutta, Life member ISTE, New Delhi, Life Member, Indian Society for mechanical Engineers, New Delhi, Associate member, Indian Institute for Industrial Engineers, Mumbai. At present he is working as director, School of Engineering \& Technology, Sri Padmavathi Mahila Visvavidyalayam, Tirupati.

Dr. K. Vijaya Kumar Reddy, is graduated in 1988, Masters in 1992 and did his Ph.D from JNTU College of Engg., Anantapur in 2000. He guided three Ph.D students and another $16 \mathrm{Ph}$. D scholars doing their research under his guidance. He has presented and published more than 100 papers in Various National \& International Conferences. He has organized 7 national level conferences \& short term courses and attended 6 National workshops during past 6 years. He had supervised the following important activities at JNTUCE, Anantapur such as NSS Programme officer, Deputy Warden, Officer in charge of hostels, Student Union coordinator, Alumni Association Secretary cum Treasurer, Officer in charge of Academic section. At Present, he is working as Professor of Mechanical Engineering at Jawaharlal Nehru Technological University, Hyderabad

Received March 2011

Accepted May 2011

Final acceptance in revised form June 2011 